\title{
Principal self-efficacy and work engagement: assessing a Norwegian Principal Self-Efficacy Scale
}

\author{
Roger A. Federici • Einar M. Skaalvik
}

Received: 28 June 2010 / Accepted: 4 April 2011 / Published online: 11 May 2011

(C) The Author(s) 2011. This article is published with open access at Springerlink.com

\begin{abstract}
One purpose of the present study was to develop and test the factor structure of a multidimensional and hierarchical Norwegian Principal Self-Efficacy Scale (NPSES). Another purpose of the study was to investigate the relationship between principal self-efficacy and work engagement. Principal self-efficacy was measured by the 22-item NPSES. Work engagement was measured by a modified version of the Utrecht Work Engagement Scale (UWES). The participants in the study were 300 principals randomly drawn from the population of Norwegian principals. Data were collected by means of an electronic questionnaire. Both the NPSES and the UWES were investigated through confirmatory factor analyses (CFA) before two structural equation models were tested. Both models specified principal self-efficacy as an exogenous variable and work engagement as an endogenous variable. The data were analyzed by means of a SEM analysis for latent variables using the AMOS 18 program. Three different models of NPSES were tested. Both a first- and second-order CFA confirmed that principal self-efficacy constitutes eight dimensions. Furthermore, both structural models had an acceptable fit to data and revealed that principal self-efficacy was positively related to work engagement. The results of the study are discussed together with limitations and suggestions for further research.
\end{abstract}

Keywords Self-efficacy · Work engagement · Motivation · Educational leadership · SEM

R. A. Federici $(\varangle) \cdot$ E. M. Skaalvik

Department of Education, Norwegian University of Science and Technology, Trondheim 7491,

Norway

e-mail: roger.federici@ntnu.no 


\section{Principal self-efficacy and work engagement: assessing a Norwegian Principal Self-Efficacy Scale}

Norwegian principals are responsible for all aspects of school management as well as future development. The exercise of these responsibilities requires the expectation to cope successfully (self-efficacy) in a number of different areas of functioning. Selfefficacy is grounded in social cognitive theory, emphasizing the evolution and exercise of human agency. The concept of human agency is built on the idea that people can exercise some influence over their life (Bandura 2006b). A vast number of studies have shown that self-efficacy influences people's performance, persistence and motivation when carrying out tasks (Bandura 1977, 1997, 2006b). Self-efficacy is defined as people's judgments of their capabilities to organize and execute courses of action required to attain designated types of performances (Bandura 1977; Bandura 1986; Bandura 1997).

Within the field of educational research, self-efficacy has primarily been studied in four different areas: student self-efficacy (e.g Bandura 1993; Schunk and Meece 2005), teacher self-efficacy (e.g. Skaalvik and Skaalvik 2007), collective teacher efficacy (e.g. Bandura 1997; Goddard et al. 2000; Skaalvik and Skaalvik 2010) and more recently principal self-efficacy (e.g. Brama 2004; Sierman Smith 2008; Smith and Guarino 2006; Tschannen-Moran and Gareis 2004, 2005). Research on principal self-efficacy is scarce and researchers have conceptualized the concept differently or measured different aspects of it. Despite differences in measures of self-efficacy, the available studies indicate that principals' self-efficacy is associated with adaptive functioning. For example, efficacious principals tend to be more persistent in pursuing goals and are more adaptable to changes (Osterman and Sullivan 1996). According to Licklider and Niska (1993), principals' self-efficacy is related to the quality of supervision of teachers (Licklider and Niska 1993). Principals' level of self-efficacy also influences their effort, work persistence and resilience in the face of setbacks (Tschannen-Moran and Gareis 2004). Moreover, Dimmock and Hattie (1996) found efficacy as a valued element for principals in a school restructuring process (Dimmock and Hattie 1996), whereas Smith et al. (2006) concluded that the quality of teaching and students' learning is influenced by the principals' efficacy (Smith et al. 2006).

Previous studies of various occupations reveal that self-efficacy is positively related to work engagement (e.g. Halbesleben 2010; Sweetman and Luthans 2010) and have consistently shown that work engagement is positively associated with concepts such as job resources (e.g. support, feedback, autonomy), personal resources (e.g. selfefficacy, organizational-based self-esteem and optimism) and job performance (e.g. extra-role performance) (Bakker 2009; Xanthopoulou et al. 2007). In the present study, work engagement is defined as a positive, fulfilling, work-related state of mind characterized by vigor, dedication and absorption (Schaufeli et al. 2002). A literature search on principal self-efficacy and work engagement indicates that there are few studies which have focused on this specific relation among principals. Still, based on previous research of different occupations (e.g. Breso et al. 2008; Prieto 2009), it seems reasonable to expect that a similar relation may be found among principals.

The purpose of the present study was twofold. In contemporary research of principal self-efficacy, it may seem as if scientists lack a well-tested and proven instrument 
for measuring this concept. There seems to be no common agreement on how the construct should be conceptualized and how it should be measured. The first purpose of the present study was therefore to develop and test the factor structure of a multidimensional and hierarchical Norwegian Principal Self-efficacy Scale (NPSES). The second purpose of the study was to investigate the relationship between principal selfefficacy and work engagement. Based on prior research, we expect to find a positive relation between the constructs.

\subsection{Social cognitive theory}

Social cognitive theory emphasizes the evolvement and exercise of human agency an idea that people can exercise some influence over what they do (Bandura 1977; Bandura 1986; Bandura 1997, 2006a). The theory postulates that individuals are engaged in their own development and that people can affect their own actions. This theoretical perspective views people as self-organizing, proactive, self-reflective and self-regulated, rather than as reactive organisms shaped by their environment. To varying degrees, people possess the skills to control their own thought patterns, emotions and actions. What they think, believe and feel create guidelines for behavior (Bandura 1986). Social cognitive theory asserts that people's perception of reality, and thus behavior, is affected by their control and influence over their lives. Individuals are considered both products and producers of their environment and social surroundings. Human functioning is viewed as the product of a dynamic interplay of personal, behavioral and environmental influences, which is the foundation of Bandura's (1986) reciprocal determinism. The concept suggests that personal factors, behavior and environmental influences create interactions that result in a triadic reciprocality.

Self-efficacy is a key element of social cognitive theory. It is defined by Bandura (1986) as "people's judgments of their capabilities to organize and execute courses of action required to attain designated types of performances" (p. 391). Self-efficacy beliefs influence the courses of action that people pursue, and is an important construct for understanding human behavior in various contexts (Bandura 1986; Bandura 1997). Self-efficacy is the individual's belief about what he or she can achieve in a given context, rather than a judgment of one's own abilities. The concept is both multidimensional and context-specific (Bong and Skaalvik 2003).

High self-efficacy promotes positive perceptions of one's own capabilities and provides information to carry out actions. Self-efficacy beliefs are of great importance for peoples' well-being in several areas. Individuals with positive efficacy beliefs tend to regard difficult tasks as challenges, whereas those who doubt their capabilities tend to consider difficult tasks as threats. Self-efficacy beliefs foster intrinsic motivation and the ability to demonstrate involvement in various activities (Bandura 1994, 1997). A characteristic of individuals with high self-efficacy may be that they set challenging goals for themselves and strive to achieve these by making and maintaining an effort. Failures are attributed to a lack of effort or knowledge, though the latter can be acquired. High self-efficacy reduces stress and decreases the likelihood of mental disorders (Bandura 1986; Bandura 1994, 1997). Individuals with low self-efficacy are generally characterized by doubts about their own abilities, and tend to withdraw from activities that are perceived as threatening or challenging. When they face difficulties 
they focus on their lack of ability to master the activity, typically reduce the amount of effort expended and give up quickly (Bandura 1986; Bandura 1994, 1997; Pajares 1997, 2002).

The sense of self-efficacy the individual possesses influences decisions of behavior in which cognitive, motivational, affective and selective processes work to transform the individual's self-efficacy into action. Self-efficacy influences self-regulatory processes in which efficacy beliefs determine how environmental opportunities and impediments are perceived. In turn, these beliefs influence choices of action, how much effort is expended on an activity and how long people will persevere when confronted with obstacles. As previously mentioned, higher levels of self-efficacy produce greater effort and persistence. Individuals' self-efficacy beliefs also influence the experience of stress and anxiety when engaging in activities (Bandura 1997; Pajares 1997). There has been extensive research on self-efficacy that supports this theory, including research on academic, cognitive, health, clinical, athletic and organizational functioning in various contexts (Bandura 1997; Pajares 1997).

Research on self-efficacy in an educational context has received increasing attention, often in studies of academic motivation and self-regulation (Pajares 1997; Schunk et al. 2008). For example, self-efficacy researchers have investigated the link between efficacy beliefs and choices in college major and career. These findings provide insight into the career development of young adolescents and can be used to develop career intervention strategies (Brown and Lent 2005; Pajares 1997; Zimmerman 1995). In addition, student self-efficacy has been shown to be related to their motivation, academic performance and achievement (e.g. Schunk and Meece 2005; Zimmerman 1995). Research on individual and collective teacher self-efficacy has shown that a teacher's self-efficacy is related to their goals and aspirations, and also predicts student motivation and achievement (e.g. Ashton and Webb 1986; Hoy and Davis 2005; Muijs and Reynolds 2002; Skaalvik and Skaalvik 2007, 2010).

\subsection{Principal self-efficacy}

It appears that several levels of the educational system have been covered within self-efficacy research, although less attention has been given to investigating principal self-efficacy. We assume that self-efficacy is also vital to leaders' success because it determines their effort and persistence in relation to a specific task as well as to the aspirations and goals they set (Bandura 1997; Gist and Mitchell 1992). Moreover, according to Chemers et al. (2000), leaders' self-efficacy is important because it affects the attitudes and performance of their followers. Leaders' efficacy beliefs are also related to their followers' commitment to organizational tasks and have a positive effect on employee's engagement (Chemers et al. 2000). One may therefore assume that principals' self-efficacy is of great importance with respect to the overall managing of schools.

Principal self-efficacy may be defined as a kind of leadership self-efficacy which is associated with a certain level of confidence in one's own knowledge, skills and abilities in association with leading others (Hannah et al. 2008). In the present study, principal self-efficacy is defined as the principals' judgments of their capabilities to plan, organize and execute tasks and deal with their relationship to people and institutions 
in their environment. Previous research on principals' self-efficacy has focused partly on the structure of the construct (e.g. Brama 2004) and partly on how it relates to other concepts (e.g. Imants and De Brabander 1996; Smith 2003; Tschannen-Moran and Gareis 2004, 2005). Some instruments try to measure principals' self-efficacy in many areas and situations that a principal might face during work, while other studies focus on a few but important aspects. Both approaches usually investigate the relation between principal self-efficacy and other concepts.

Brama (2004) tested a three-dimensional model to investigate the structure of principal self-efficacy. The model was comprised of organizational skills, human skills and technical skills. A reliability analysis and exploratory factor analysis did not statistically support this model. In a later study, data were analyzed by means of an exploratory and confirmatory factor analysis. These results supported a five-component construct of principal self-efficacy comprised of efficacy for general managing, efficacy for leadership, efficacy for human relations, efficacy for managing school relationships with the environment, and instructional efficacy. The author emphasized that the concept is culture-dependent and that the components are to be reconsidered in periods of organizational change within the educational system or changes in principals' work instructions (Brama 2004). A similar measure was developed by TschannenMoran and Gareis (2004) called the Principal Sense of Efficacy Scale (PSES). This instrument was based on their previous work with the Teacher Self-Efficacy Scale (TSES) (Tschannen-Moran and Hoy 2001). The construct validity of the scale was assessed using a measure of work alienation (Forsyth and Hoy 1978). This survey included items concerning various aspects of the principals' context and work alienation. Using principal component factor analysis (PCA), the original 50-item questionnaire for personal efficacy was reduced to 18 items. Three factors emerged: efficacy for management, efficacy for instructional leadership and efficacy for moral leadership. All dimensions were significantly and negatively correlated with work alienation at $\mathrm{r}=-.37,-.41,-37(p<.01)$, respectively. The researchers concluded that this scale was promising for future research on how to measure principals' sense of efficacy (Tschannen-Moran and Gareis 2004, 2005).

Research on principal self-efficacy usually includes measures of multidimensional self-efficacy in order to capture different aspects of principals' work. A problem with both of the aforementioned studies as well as other studies may be that the instruments for capturing principals' self-efficacy are reduced to only a few dimensions or do not take into consideration the hierarchal structure that characterizes leaders' self-efficacy (Hannah et al. 2008). Thus, they may not capture all the important aspects of the principals' work. One purpose of the present study was therefore to develop an instrument for measuring principals' self-efficacy with a broader variety of their functions and responsibilities.

\subsection{Work engagement}

Different concepts of work engagement have been present for more than two decades and may particularly be seen in the consulting and development business. Thus, the concept is often expressed in conjunction with organizational development and human relations departments. The idea of employee engagement was probably first introduced 
commercially in the 1990s by the Gallup organization, which conceptualized engagement as the individual's involvement, satisfaction and enthusiasm for work (Schaufeli and Bakker 2010). More recently, attention to work engagement has increased in academic contexts. Within this field, work engagement is often associated with the paradigm of positive psychology, focusing on people's strengths and optimal functioning. This may be viewed in opposition to traditional psychology, which is often regarded as having a focus on mental illness instead of mental wellness (Bakker et al. 2008; Schaufeli and Bakker 2010).

According to Schaufeli and Bakker (2010), there is no universal consensus on how the concept of work engagement should be defined. At first glance, it seems possible to identify a distinction between definitions of work engagement in academic research and business. The academic definition is often related to the work role or work activity, whereas the business focus is on the individual's or group's relation to the organization (Schaufeli and Bakker 2010). The latter definition does not necessarily capture the academic content of work engagement, but may have parallels with more traditional concepts such as job involvement or job satisfaction (Schaufeli and Bakker 2010).

The concept of work engagement originated in academic research in the 1990s with the work of Kahn (1990), who conceptualized work engagement in terms of employees who put a great amount of effort into their work because they felt some type of identification with the work itself or the work role (Kahn 1990). Rothbard (2001) derived another perspective from the work of Kahn by developing a twodimensional motivational concept of attention and absorption (Rothbard 2001). This attention dimension consisted of an individual's cognitive availability and the amount of time spent thinking about work. Absorption referred to the intensity of one's focus on a role (for more extensive reading see Rothbard 2001). This initial research seems to be both the foundation and source of inspiration for contemporary views on work engagement.

Schaufeli and Bakker (2010) describe two different but related views of work engagement that they consider to be a positive work-related state of well-being or fulfillment (Bakker et al. 2008). The first approach considers work engagement as the opposite or positive antithesis of burnout, a measurement model with three dimensions consisting of exhaustion, cynicism and reduced professional efficacy. Low scores on the first two dimensions and high scores on professional efficacy indicate engagement (Maslach et al. 2001). The alternative view considers work engagement as a separate concept, which correlates negatively with burnout. In this view, work engagement is defined as: "A positive, fulfilling, work-related state of mind that is characterized by vigor, dedication, and absorption" (Schaufeli et al. 2002). According to this definition, work engagement refers to a feeling of fulfillment and is a persistent and pervasive affective-cognitive state not focused on any particular object, event, individual or behavior (Schaufeli and Bakker 2010; Schaufeli et al. 2006). People who experience work engagement have a sense of an energetic and effective connection with their work activities, and see themselves as being able to deal well with the demands of their job (Schaufeli and Bakker 2004).

The three dimensions that constitute work engagement are described separately with different properties. Vigor is characterized by high levels of energy and men- 
tal strength. The individual has a desire to put some effort into work and possesses the ability to persist in the face of difficulties. Dedication refers to being involved in work and experiencing significance, enthusiasm, inspiration, pride and challenge, while absorption refers to being concentrated and involved in one's own work (Bakker et al. 2008; Schaufeli and Bakker 2010; Schaufeli et al. 2006, 2002).

The Utrecht Work Engagement Scale (UWES) is based on a definition that includes vigor, dedication and absorption (Bakker et al. 2008; Schaufeli and Bakker 2010; Schaufeli et al. 2006, 2002). This three-dimensional instrument consists of a full version containing 17 items, a short version containing nine items and a student version (Schaufeli and Bakker 2010). Various studies have been conducted to investigate the discrepancy between the UWES definition of work engagement and related concepts. This concept is different from burnout (Schaufeli and Bakker 2010; Schaufeli et al. 2002), job involvement (Hallberg and Schaufeli 2006), organizational commitment (Hallberg and Schaufeli 2006) and workaholism (Schaufeli et al. 2008).

Previous research within the UWES framework has documented that work engagement is positively related to different job characteristics such as resources and motivators (Schaufeli and Bakker 2004). Resources and motivators include support from one's co-workers and superiors, performance feedback, coaching, job autonomy, task variety and training facilities (Demerouti et al. 2001a; Salanova et al. 2003; Schaufeli and Bakker 2004, 2010). Research on the consequences from the experience of work engagement has demonstrated that the concept is related to positive attitudes towards work. This includes job satisfaction, commitment and low turnover intentions (Demerouti et al. 2001a; Schaufeli and Bakker 2004). Additionally, work engagement is also related to positive organizational behavior such as personal initiative, learning motivation (Sonnentag 2003) and extra-role behavior (Salanova et al. 2005). Finally, in a study by Salanova et al. (2005) of Spanish hotels and restaurants, the researchers found that work engagement was positively related to job performance. The study examined the mediating role of the service climate in the prediction of employee performance and customer loyalty. They found that organizational resources and work engagement predict the service climate, which in turn predicts employee performance and customer loyalty (Salanova et al. 2005).

\subsection{Self-efficacy and work engagement}

Research on self-efficacy has shown that efficacy beliefs predict motivational responses such as effort and persistence, whereas self-efficacy is negatively related to stress and anxiety (Bandura 1977, 1982, 1994, 1997, 2001). Hence, it is reasonable to expect a positive relation between self-efficacy and work engagement. This expectation is supported by several studies. Attention has been devoted to the role of self-efficacy in the Job Demands-Resources Model (JD-R) (Demerouti et al. 2001b). Prieto (2009) expanded the JD-R model and regarded self-efficacy as a personal resource in the prediction of work engagement. The results revealed that self-efficacy significantly predicted work engagement as measured by the UWES (Prieto 2009). Another paper (Sweetman and Luthans 2010) discussed the relation between psychological capital and work engagement. Psychological capital can be thought of 
as a concept similar to personal resources which include self-efficacy, optimism, hope and resilience (Sweetman and Luthans 2010). According to Sweetman and Luthans' discussion, these concepts facilitate work engagement, and they argued that efficacy is the most important psychological mechanism for producing positive work-related outcomes. This type of relation is also supported in a meta-analysis by Halbesleben (2010). The meta-analysis searched for correlations between various concepts and work engagement. In the analysis, self-efficacy was regarded as a resource which was hypothesized to be positively associated with work engagement. The analysis revealed that self-efficacy had an estimated correlation of .50, $(p<.01)$ to overall engagement.

A study by Xanthopoulou et al. (2007) examined the relation between personal resources (self-efficacy, organizational-based self-esteem and optimism) and work engagement in a study of Dutch technicians. The results showed that engaged employees are highly self-efficacious, and believe they are able to meet the demands they face in a broad array of contexts (Xanthopoulou et al. 2007). Finally, and most relevant to the present study, Bakker et al. (2006) found in a study of female principals that those with the most personal resources scored highest on work engagement. In particular, they found that resilience, self-efficacy and optimism contributed to both work engagement and a positive relation between principals' work engagement and teacher ratings of performance and leadership. Furthermore, the analysis revealed that engaged principals scored higher on in-role and extra-role performance and that work engagement was also strongly related to creativity. The higher the principals' levels of work engagement, the better they were able to come up with a variety of ways to deal with work-related problems. Finally, engaged school principals were seen as transformational leaders - able to inspire, stimulate and coach their co-workers (Bakker et al. 2006).

\section{The present study}

The role of the Norwegian principal has been subjected to major changes within the Norwegian school system over the last five decades. The need for professional leadership has been emphasized since the 1980s when the government called for a clearer distribution of authority and administrative management. This took place as a result of the emerging New-Public Management governance of the public sector, with target-oriented management and profit responsibility (Møller 2004; Møller and Fuglestad 2006). In the 1990s, the character of governance evolved towards giving increased autonomy to school leaders. The principal's work descriptions changed and new areas of responsibility such as mercantile and personnel administration arose (Benestad and Pleym 2006; Møller 2004; Møller and Fuglestad 2006). Since the millennium, even larger changes have appeared in the governance of education. The previous idea of organizing an equivalent education through detailed governance has been replaced with trust. This trust is based on the assumption that teachers, principals and school owners have the necessary competence for implementing the national objectives for education. Keywords in national governance are: common goals, results, evaluation, clear location of responsibility and increased local freedom. 
Norwegian principals are supposed to monitor and enhance activities in schools. They are responsible for all aspects of school management as well as for future development. These responsibilities require well-developed social and leadership skills, mercantile skills, and instructional and administrative skills (Benestad and Pleym 2006). In addition, principals have to relate to internal and external expectations that arise from various locations, e.g. politicians, the press, school owners, parents, employees and pupils. The work content has changed tremendously over the past decades, and new tasks and areas of responsibility have become apparent. This expanded area of responsibility is believed to have consequences for role implementation.

One purpose of the present study was to develop an instrument that could capture self-efficacy in relation to different areas of responsibilities and relations. Bandura (2005) criticized the use of general and non-specific self-efficacy scales. Such scales have little predictive value, as an individual's general efficacy is usually not specific enough for the actual domain under study. For that reason, scales for measuring principals' self-efficacy must be tailored to the specific domain and reflect specific tasks and responsibilities (Bandura 2005). The development of the NPSES was therefore initiated with five semi-structured qualitative interviews with principals from different public elementary schools and middle schools $\left(1^{\text {st }}-10^{\text {th }}\right.$ grade $)$ from two Norwegian counties.

The main objective of the interviews was to obtain a description of a typical working day. Data collected from the interviews was sorted into categories of tasks and responsibilities that the principals perceived as important aspects of their functioning. Van Etten et al. (2008) describe this as an inductive qualitative research design in which researchers approach their study with a vague hypothesis; in this case, it was an idea of what categories would appear. A primary focus was to induce categories that are viewed as credible because they are based on analyses of data and then tested in a subsequent deductive quantitative study (Van Etten et al. 2008). Eight categories were derived from the interviews and a 22 -item questionnaire was developed on the basis of these categories.

In the present study we report on three models of the NPSES and the UWES, respectively, using a first- and second-order confirmatory factor analysis (CFA). We then use structural equation modeling (SEM) to analyze two different models of relationships between self-efficacy and work engagement. Finally, we present the mean scores for each dimension of the NPSES and the UWES, respectively.

\section{Method}

\subsection{Participants and procedure}

Participants in the study were principals of public elementary schools and middle schools $\left(1^{\text {st }}-10^{\text {th }}\right.$ grades $)$ in Norway. A total of 569 public schools were randomly drawn from a list containing 2,900 schools, representing all the public schools in Norway. Of the 569 principals who were invited to participate in the survey, 300 responded positively. This amounts to a response rate of $53 \%$, which may be considered low with respect to selectivity. However, considering the randomly drawn sample, we assume 
that the non-responses were random. This is supported by the distribution of gender and age in the sample compared to this distribution within the population of Norwegian principals.

Data were collected using an electronic questionnaire. Information about the study and an invitation to participate were first distributed by mail to each of the respondents. Two weeks later, each respondent received a personal link to the survey which was sent by e-mail.

The sample consisted of $52.8 \%$ males and $47.2 \%$ females. The age of the principals ranged from 32 to 69 years old, and the mean age was 52 years. The average amount of teaching experience before becoming a principal was 19 years and the average number of years of managing experience was 11 . The sample consisted of principals from different school levels: $58.7 \%$ from elementary schools, $15.3 \%$ from middle schools and $19.7 \%$ from elementary and middle schools combined. School size varied from 6 to 1,300 pupils, with an average of 232 .

\subsection{Instruments}

All instruments in the present study were developed and administered in Norwegian. Examples of sample items in the Appendix represent translations from Norwegian into English.

\subsubsection{Principal self-efficacy}

Principal self-efficacy was measured by a multidimensional 22-item Norwegian Principal Self-Efficacy Scale. The scale consisted of eight dimensions with a different number of items on each subscale. The dimensions were all developed to cover various aspects of a principal's work that were assumed to be relevant. Item construction was conducted following Bandura's recommendations (Bandura 1997, 2005). Since self-efficacy is concerned with perceived capabilities, the items should contain verbs such as "can" or "be able to" in order to make it clear that the item asked for mastery expectations because of personal competence. The subject in each statement should be "you" since the aim was to assess each principal's subjective belief about his or her own capability. Responses were given on a seven-point scale ranging from "Not certain at all" (1) to "Absolutely certain" (7).

Instructional leadership consisted of two items with a Cronbach's alpha of .71. An example of an item is: "How certain are you that you can initiate, plan and carry out instructional development?" This dimension attempts to capture the principal's mastery expectations in relation to managing and developing the school's educational platform. Economic management consisted of two items with a Cronbach's alpha of .88. An example of an item is: "How certain are you that you can keep track of the school's finances?" These items attempt to examine the mercantile side of principals' self-efficacy. Norwegian principals are responsible for the school's finances and are held accountable in times of deficits. Three of the eight dimensions of the NPSES focused on principals' expectations of being able to cooperate effectively with persons or institutions outside or external to the school where they were employed. 
These are: relation to municipal authority, parental relations and relation to local community. The municipal authority is the principals' employer. This dimension consists of two items, with an example of an item being: "How certain are you that you can collaborate with the municipal authority about future directions for the school?" Parental relations also consist of two items in which the questions ask about conditions such as: "How certain are you that you can develop a good cooperation between school and home?" The third dimension that can be considered as an external relation is the relationship with the local community. This dimension mainly focuses on the relationship with local businesses, groups or institutions such as museums and other resources in the local community such as outdoor areas or associated individuals, and consists of three items. An example of an item is: "How certain are you that you can maintain contact and cooperate with local businesses?" The three dimensions had a Cronbach's alpha of $.52, .82$ and .84 , respectively. Despite its low alpha value, the dimension concerning the relationship with municipal authority was retained on both statistical and theoretical bases. The correlation between the two items was $.35(p<.01)$, and removing the dimension or one of the items did not contribute to a better fit using CFA. The theoretical argument is based on the importance of this relationship as noted in the interviews and the emphasis of this relationship in governance documents.

The three remaining dimensions of the NPSES are self-efficacy for administrative management, teacher support and school environment, respectively. Administrative management consists of four items, with one example: "How certain are you that you can follow up and implement all decisions taken?" The Cronbach's alpha for this dimension was .82. Teacher support consisted of two items with a Cronbach's alpha of .78. This dimension focuses on the principals' expectations of being able to support teachers who are struggling. An example of an item is: "How certain are you that you can attend to and support teachers who are struggling with strain or exhaustion" The last dimension of the NPSES is school environment, which consists of five items and focuses on both teachers and pupils. The content of this dimension tries to capture principals' self-efficacy for creating a good school environment and positive climate. Some examples of items are: "How certain are you that you can develop a good psychosocial environment for the pupils?" and "How certain are you that you can develop a school in which all teachers experience well-being?" Cronbach's alpha on this dimension was .89 .

\subsubsection{Work engagement}

The principals' work engagement was measured by the Utrecht Work Engagement Scale (UWES). The UWES is available in different languages and two main versions exist: the full and the short version, with 17 and 9 items on each scale, respectively (Schaufeli and Bakker 2004). The different versions of the instrument have been tested in various countries, where the instrument has exhibited both a stability and factorial invariance between nations and occupational groups. In addition, the threefactor structure repeatedly shows a best fit to data compared to a one-factor structure using confirmatory factor analysis, although the three dimensions are usually strongly 
correlated. According to Schaufeli and Bakker (2010), it could be difficult to identify these dimensions using an exploratory factor analysis. They conclude that work engagement measured by the UWES is a unitary construct constituted of the three dimensions, so it might be reasonable to use the total score of the UWES as an indicator of work engagement.

In the present study, we used a previously translated Norwegian version of the UWES (Schaufeli and Bakker 2004) that consists of both the full and short versions, and we took advantage of the short one. According to Schaufeli and Bakker (2004b), the short version was developed by analyzing multiple samples from the full version, in which a selection of items for the short version was partially made on the basis of regression analyses. The short version is also constituted by the three dimensions (vigor, dedication and absorption). The dimensions consist of three items each and responses were given on a seven-point scale ranging from "Never" (1) to "Daily" (7).

Vigor refers to high levels of energy and resilience, investment of effort, perseverance and persistence in the face of difficulties. An example of an item is: "At work, I feel like I'm bursting with energy." This dimension had a Cronbach's alpha of .90. The dimension of dedication had a Cronbach's alpha of .86. An example of an item is: "I am enthusiastic about my job." Dedication attempts to capture a principal's experience of feeling enthusiastic, proud, inspired and challenged by work. The last dimension, absorption, refers to being totally and happily immersed in work and having difficulties detaching oneself from it. The Cronbach's alpha was .78. An example of an item is: "I am immersed in my work."

\subsection{Data analysis}

The data were analyzed by means of a confirmatory factor analysis (CFA) and structural equation modeling (SEM). These methods are powerful statistical tools for examining the relationship between latent constructs and test a priori hypotheses regarding relationships between observed and latent variables. This methodology takes a confirmatory approach to the analysis of data (Byrne 2010; Jackson et al. 2009). Since CFA is part of the larger family of SEM, it usually plays an essential role in evaluating the measurement model before a structural analysis is conducted. Structural analysis is then used for specifying and estimating models of linear relationships between both observed and latent variables (Jackson et al. 2009; MacCallum and Austin 2000).

When conducting SEM, the analysis produces an estimated population covariance matrix based on the model specified. A key element of SEM is to assess whether the model produces an estimated matrix consistent with the sample matrix (Tabachnick and Fidell 2007). This consistency is investigated through various measurement indices of goodness of fit. If the goodness of fit is adequate, it supports the plausibility of the model specified. Different measures of fit are available and are assessed through different indices such as CFI, IFI, TLI and RMSEA, as well as chi square test-statistics. For the CFI, IFI and TLI indices, values greater than .90 are typically considered acceptable, whereas values greater than .95 indicate a good fit to the data (Byrne 2010; 
$\mathrm{Hu}$ and Bentler 1999). For well-specified models, an RMSEA of .06 or less indicates a good fit (Hu and Bentler 1999).

The data were initially screened for univariate and multivariate normality and outliers using PASW Statistics 18 and AMOS 18. The data set contained missing data that were assumed to be missing completely at random. A missing value analysis was conducted with PASW Statistics 18. The results revealed that there were no variables with $1.7 \%$ or more of missing values. Little's MCAR test was used to test whether data were missing completely at random. The test showed a non-significant result $(\chi 2(422, N=300)=394.20, p=.83)$.

Further analyses were conducted using AMOS 18 software. Maximum likelihood estimation was employed to estimate all models based on their corresponding covariance matrix. Since some of the features in AMOS would not be available with missing data, analyses initially used an imputed data set. The imputation of missing data was conducted using AMOS' integrated function, which creates a new dataset with complete data. This regression imputation uses linear regression to predict the unobserved values for each case as a linear combination of the observed values for that same case. Predicted values are then plugged in for the missing values (Arbuckle 2009). The results in the present study are based on the original dataset with missing data, which showed more or less identical results compared to the imputed set. When AMOS 18 is confronted with missing data, the software performs a state-of-the-art estimation using full information maximum likelihood instead of relying on ad hoc methods such as list- or pair-wise deletion (Arbuckle 2009).

\section{Results}

\subsection{Measurement model: NPSES}

The factor structure of the NPSES was explored by testing three theoretical models by means of first- and second-order confirmatory factor analyses. Model 1 consisted of one primary factor with loadings on all 22 observed items. This model was tested to ascertain whether principals' self-efficacy could be treated as a one-dimensional construct. Model 2 defined eight correlated primary factors corresponding to the eight theoretical dimensions. Model 3 defined eight primary factors and one second-order factor underlying the primary factors. The three theoretical models are presented in Fig. 1.

Model 1 did not fit the data $(\chi 2(209, N=300)=1220.92, p<.001, \mathrm{CMIN} / \mathrm{DF}=$ 5.842 , $\mathrm{RMSEA}=0.127, \mathrm{IFI}=0.696, \mathrm{TLI}=0.662$, and $\mathrm{CFI}=0.694)$. Models 2 and 3 had a good fit to the data $(\chi 2(181, \mathrm{~N}=300) 309.23, \mathrm{p}<.001, \mathrm{CMIN} / \mathrm{DF}=$ $1.708, \mathrm{RMSEA}=0.049, \mathrm{IFI}=0.962, \mathrm{TLI}=0.951$, and $\mathrm{CFI}=0.961)$ for Model 2 and $(\chi 2(201, \mathrm{~N}=300) 372.82, \mathrm{p}<.001, \mathrm{CMIN} / \mathrm{DF}=1.855, \mathrm{RMSEA}=0.053, \mathrm{IFI}=$ $0.949, \mathrm{TLI}=0.940$, and CFI $=0.948$ ) for Model 3. All regression weights in Models 2 and 3 were significant at $p<.001$. The correlations in Model 2 are presented in Table 1.

Results from the confirmatory factor analyses verify that principal self-efficacy is a multidimensional construct. In the present study, principal self-efficacy consists of 

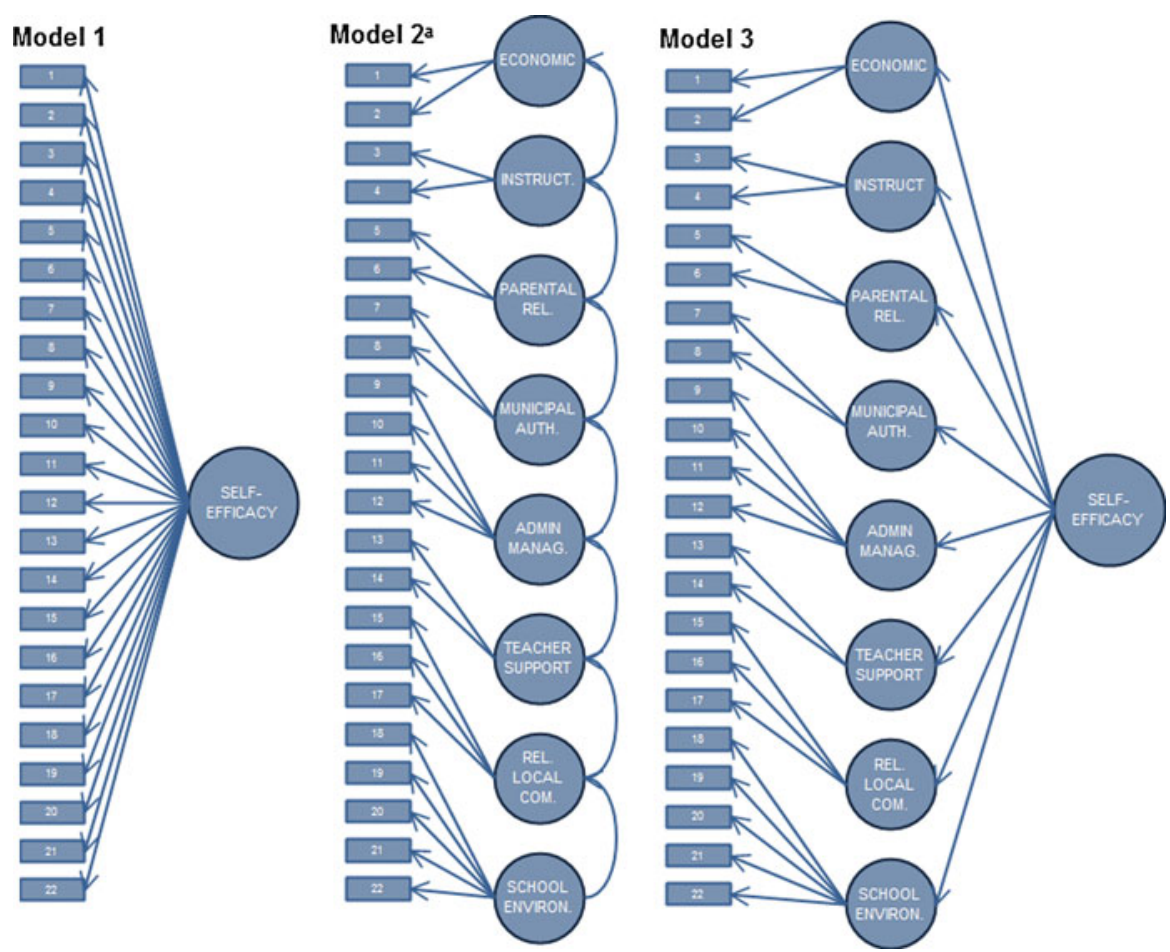

Fig. 1 Three hypothesized models of the NPSES. Model 1: one primary factor with regression weights on the 22 observed items. Model 2: eight correlated primary factors and their respective items. Model 3: eight primary factors and one second-order factor. ${ }^{\mathrm{a}}$ All latent variables are internally correlated

Table 1 Correlations between the eight dimensions of the NPSES in theoretical Model 2

\begin{tabular}{|c|c|c|c|c|c|c|c|c|}
\hline Dimension & 1 & 2 & 3 & 4 & 5 & 6 & 7 & 8 \\
\hline 1. Economic management & - & & & & & & & \\
\hline 2. Instructional leadership & .278 & - & & & & & & \\
\hline 3. Municipal authority & .403 & .606 & - & & & & & \\
\hline 4. Parental relations & .341 & .725 & .563 & - & & & & \\
\hline 5. Local community & .293 & .299 & .634 & .427 & - & & & \\
\hline 6. Admin. management & .470 & .691 & .722 & .684 & .487 & - & & \\
\hline 7. Teacher support & .286 & .675 & 648 & .596 & .313 & .570 & - & \\
\hline 8. School environment & .410 & .779 & .595 & .701 & .421 & .773 & .636 & - \\
\hline
\end{tabular}

All correlations are significant at $p<.001$

eight correlated primary factors with 22 corresponding items. The correlations vary from moderate to strong. Self-efficacy can be regarded as both domain-specific and multidimensional, and the second-order analysis also indicates that the concept is constituted by a more general domain-specific experience of self-efficacy. 


\subsection{Measurement model: UWES}

Since principals' work engagement was measured by a translated version of the UWES, initial analyses consisted of exploratory factor analyses (EFA) to investigate whether the three predicted dimensions would actually appear. The results from EFA (maximum likelihood with Varimax rotation) indicated that work engagement in this case consisted of only two factors based on eigenvalues greater than 1 . Thus, further analysis became necessary, and the procedure chosen was a confirmatory factor analysis that took the result from EFA into consideration.

Three models of the UWES were tested. Model 1 defined work engagement in terms of three correlated primary factors, which are in accordance with theory and previous research. Model 2 defined work engagement as a single first-order factor with loadings on the nine observed items. Model 3 defined work engagement as a first-order factor consisting of seven items, in which the two items that constituted Factor 2 on EFA were excluded. Models 1 and 2 did not fit data with goodness of fit indices of, respectively, $(\chi 2(24, \mathrm{~N}=300)=235.25, \mathrm{p}<.001, \mathrm{CMIN} / \mathrm{DF}=9.802, \mathrm{RMSEA}=0.172, \mathrm{IFI}=$ $0.898, \mathrm{TLI}=0.846$, and $\mathrm{CFI}=0.897)$ for Model 1 and $(\chi 2(27, \mathrm{~N}=300)=359.70$, $\mathrm{p}<.001, \mathrm{CMIN} / \mathrm{DF}=13.22, \mathrm{RMSEA}=0.203, \mathrm{IFI}=0.839, \mathrm{TLI}=0.785$, and $\mathrm{CFI}=$ 0.839) for Model 2. Results from the analysis of Model 3 indicated a good fit $(\chi 2(12, \mathrm{~N}=300)=23.86, \mathrm{p}<.001, \mathrm{CMIN} / \mathrm{DF}=1.989, \mathrm{RMSEA}=0.057, \mathrm{IFI}=$ 0.993 , TLI $=0.988$, and CFI $=0.993)$. All regression weights in Model 3 were significant at $\mathrm{p}<.001$.

The results from the CFA were somewhat unexpected with regard to theory and previous research. However, according to Schaufeli and Bakker (2010), work engagement measured by the UWES may be regarded as a unitary construct in which the total score can be used as an indicator. In this case, two items were unsound and therefore removed from the analysis.

\subsection{SEM: relation between the NPSES and the UWES}

According to Jackson et al. (2009), challenges with SEM often occur because the measurement models of the structural analysis consist of issues that are not properly investigated. Measurement models should first be examined, and it is essential that they reflect the desired constructs under study. The initial analyses consisted of an evaluation of the measurement models of the NPSES and the UWES, respectively. The analyses revealed that two models of the NPSES and one model of the UWES had an acceptable goodness of fit. Further analyses focused on the relation between self-efficacy and work engagement in which two theoretical models were analyzed by means of SEM. Both models specify self-efficacy as a predictor of work engagement. Models 1 and 2 are shown in Figs. 2 and 3.

Model 1 consisted of two first-order measurement models, the NPSES and the UWES, respectively. The NPSES consisted of eight latent exogenous variables (the eight dimensions of the NPSES) predicting the latent endogenous variable work engagement. The model had an acceptable fit to data $(\chi 2(340, N=300)=574.74$, $p<.001, \mathrm{CMIN} / \mathrm{DF}=1.690, \mathrm{RMSEA}=0.048, \mathrm{IFI}=0.955, \mathrm{TLI}=0.946$, and $\mathrm{CFI}=$ 0.955). Only two dimensions of the NPSES contributed significantly to work 


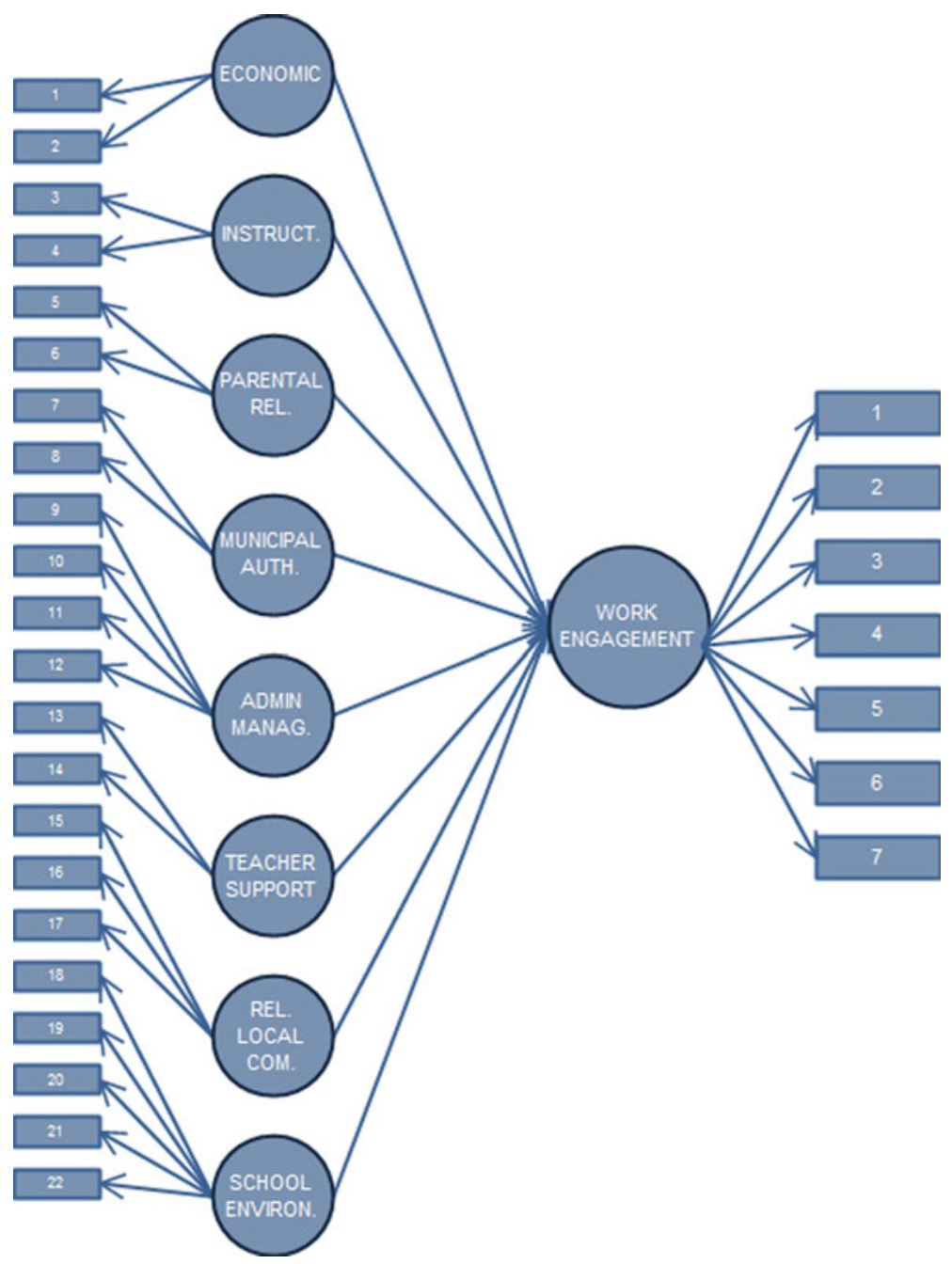

Fig. 2 Theoretical model of the relation between the NPSES and the UWES. Eight correlated primary factors of the NPSES and the first-order factor of the UWES

engagement: Instructional leadership $(\beta=.50, p<.05)$ and administrative management. $(\beta=.37 p<.05)$. Estimates of non-standardized and standardized regression weights for all the variables and the squared multiple correlations for work engagement are presented in Table 2.

The results presented in Table 2 were somewhat unexpected and may be due to multicollinearity between some or all dimensions in the NPSES. Remember that in Table 1 all latent variables were significantly correlated in the first-order CFA of Model 2 (NPSES). Multicollinearity does not reduce the predictive power of the model as a whole, but it may affect the estimation of regression weights for each dimension. Models with multicollinearity tend to estimate the independent variables with less 


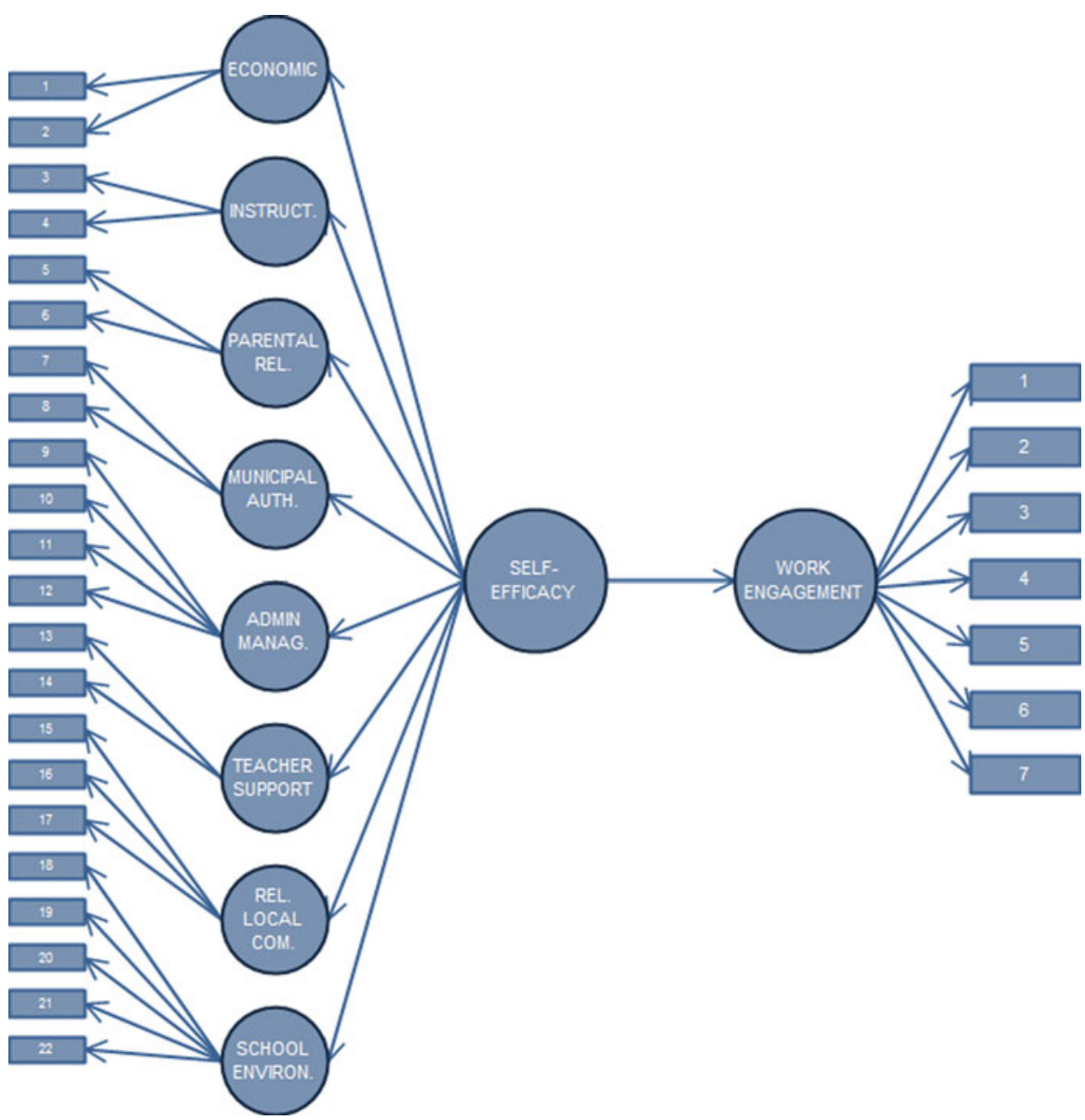

Fig. 3 Theoretical model of the relation between the NPSES and the UWES. The second-order model of the NPSES and the first-order factor of the UWES

precision than if the predictors were uncorrelated with one another. This means that multicollinearity does not bias the results, but instead produces larger standard errors that lead to non-significant results. On that basis, we conducted SEM analyses for each individual dimension to investigate the relation with work engagement. All regression weights predicted work engagement significantly when we used $p<.01$. Estimates of non-standardized and standardized regression weights for all the variables and squared multiple correlations for work engagement are presented in Table 3.

Based on the unexpected results from the structural analysis of Model 1 and previous analyses in which two CFA models of the NPSES resulted in an acceptable fit, we decided to also test the second-order model in relation to work engagement. Model 2 consisted of one second-order exogenous variable (self-efficacy) and nine first-order latent endogenous variables (the eight dimensions of the NPSES and work engagement). This model also had an acceptable fit to the data $(\chi 2(367, N=300)=$ 
Table 2 Eight dimensions of the NPSES and their corresponding regression weights on engagement

$* * p<.05$

Table 3 Summary of eight separate SEM analyses testing the relation between each dimension of NPSES and engagement

$* * * p<.001, * p<.01$

\begin{tabular}{llll}
\hline Latent variable & $\begin{array}{l}\text { Unstandard- } \\
\text { ized factor } \\
\text { loadings }\end{array}$ & $\begin{array}{l}\text { Standardized } \\
\text { factor loadings }\end{array}$ & $R^{2}$ \\
& & \\
\hline
\end{tabular}

Engagement

\begin{tabular}{lcr} 
Economic management & .013 & .020 \\
Instructional leadership & $.654^{* *}$ & .498 \\
Municipal authority & -.104 & -.103 \\
Parental relations & .056 & .053 \\
Local community & .038 & .044 \\
Admin. management & $.415^{* *}$ & .368 \\
Teacher support & -.202 & -.173 \\
School environment & -.240 & -.175 \\
\hline
\end{tabular}

\begin{tabular}{llll}
\hline Latent variable & $\begin{array}{l}\text { Unstandard- } \\
\text { ized factor } \\
\text { loadings }\end{array}$ & $\begin{array}{l}\text { Standardized } \\
\text { factor loadings }\end{array}$ & $R^{2}$ \\
\hline Economic management & $.090^{*}$ & .167 & .028 \\
Instructional leadership & $.720^{* * *}$ & .485 & .236 \\
Municipal authority & $.224^{*}$ & .272 & .272 \\
Parental relations & $.373^{* * *}$ & .385 & .148 \\
Local community & $.178^{* * *}$ & .209 & .044 \\
Admin. management & $.548^{* * *}$ & .470 & .221 \\
Teacher support & $.293^{* * *}$ & .245 & .060 \\
School environment & $.530^{* * *}$ & .389 & .151 \\
\hline
\end{tabular}

$652.91, p<.001, \mathrm{CMIN} / \mathrm{DF}=1.779, \mathrm{RMSEA}=0.051, \mathrm{IFI}=0.945, \mathrm{TLI}=$ 0.939 , and CFI $=0.945$ ). In this model, principal self-efficacy predicted work engagement with a standardized regression weight of $\beta=.48, p<.001$ explaining $23 \%$ of the variance of work engagement.

\subsection{Mean scores of the NPSES and the UWES}

The analyses of the NPSES and the UWES revealed that the theoretical models had an acceptable fit to the data. As a result, we therefore computed mean scores of the observed variables for each dimension of the NPSES and the UWES. The mean scores and standard deviations are presented in Table 4.

Remember that responses were given on a seven-point scale for both the NPSES and the UWES. The results presented in Table 4 indicate that the principals in the present study rate themselves slightly higher than the theoretical mean on both self-efficacy 
Table 4 Means scores of the NPSES and the UWES

\begin{tabular}{llll}
\hline Variable & $N$ & $M$ & SD \\
\hline NPSES & & & \\
Economic management & 300 & 5.48 & 1.21 \\
Instructional leadership & 295 & 5.52 & 0.87 \\
Municipal authority & 299 & 4.89 & 1.02 \\
Parental relations & 297 & 5.81 & 0.80 \\
Local community & 298 & 4.53 & 1.11 \\
Admin. management & 284 & 5.11 & 0.84 \\
Teacher support & 295 & 5.56 & 0.85 \\
School environment & 292 & 5.44 & 0.71 \\
UWES & & & \\
Work engagement & 296 & 6.03 & 0.93 \\
\hline
\end{tabular}

and work engagement. For principal self-efficacy, there seem to be no major differences between the dimensions, except for a lower means on relation with municipal authority and relation with local community.

\section{Discussion}

In numerous studies, self-efficacy has been shown to predict cognitions as well as emotions and behavior. For instance, self-efficacy has been demonstrated to be positively related to students' goals and aspirations, choices, effort, and persistence in the face of difficulties and academic performance. Studies of teachers also show that teacher self-efficacy predicts teachers' goals, motivation, job satisfaction and well-being, as well as their students' motivation and achievement.

Less attention has been given to principal self-efficacy, and there is also a lack of valid instruments measuring principal self-efficacy tailored to a variety of their functions and responsibilities. One purpose of this study was therefore to develop and test the factor structure of a multidimensional and hierarchical scale for measuring principals' self-efficacy in a variety of their functions and responsibilities. A second purpose was to explore the relation between self-efficacy and work engagement among Norwegian principals.

Based on interviews with principals in Norwegian elementary and middle schools, we identified eight areas of principals' functioning and responsibilities. The Norwegian Principal Self-efficacy Scale (NPSES) was then developed to measure the eight different dimensions of principal self-efficacy. A confirmatory factor analysis defining a single primary factor did not fit the data, whereas a model defining eight primary factors did have a good fit. When testing a third model, we also found support for a strong second-order self-efficacy factor underlying the eight dimensions.

These analyses clearly support the conceptualization of principal self-efficacy as a multidimensional construct. We found strong support for eight separate, but correlated dimensions. Consequently, one cannot adequately measure principal self-efficacy 
without taking into consideration the variety of responsibilities given to school principals. The NPSES contributes to such a measure and may improve research on principal self-efficacy. However, it is tailored to the responsibilities of principals in Norwegian schools and needs to be validated in other countries.

The fact that we found eight separate but correlated dimensions of principal self-efficacy has implications for both educational practice and research. Given that self-efficacy predicts cognitions as well as emotions and behavior, e.g. principals' prioritizing, choices and effort, our analyses indicate that it is important that principals have strong efficacy beliefs in a number of areas of functioning. We may speculate that principals who have high self-efficacy beliefs in some areas and lower self-efficacy in other areas may give priority to those areas in which they have the strongest expectations of mastery. Hence, our results may have implications for both the selection and training of principals. In particular, the training of principals should cover a wide range of areas of responsibility. One could also question whether school principals have been given a range of responsibilities that is too broad. For instance, principals in Norwegian schools have a range of responsibilities that used to be maintained by the local school authority, such as responsibility for the school finances, for maintaining the buildings, for employing teachers and for developing a local curriculum. Although these reflections are speculations beyond our data, they point to important questions for future research as well as for practical school governance.

Although we found support for eight separate dimensions of principal self-efficacy, we also found support for a strong second-order factor underlying the eight dimensions. This indicates that in addition to self-efficacy beliefs for specific areas of functioning, school principals also have a more general domain-specific experience of self-efficacy. These findings make the instrument particularly useful for research purposes. The NPSES may be used to study the relations between a second-order selfefficacy factor and other constructs, though it may also be used to study the impact of specific dimensions of self-efficacy for different areas of principals' functioning. An important question for future research is whether principal attrition is most strongly related to their general domain-specific self-efficacy or to specific aspects of principal self-efficacy.

A second purpose of this study was to explore the relation between principal selfefficacy and work engagement. Work engagement was measured by a short seven-item version of the Utrecht Work Engagement Scale. Based on exploratory as well as confirmatory factor analyses, work engagement was treated as a single first-order factor. We tested two models by means of structural equation modeling to investigate the relation between self-efficacy and work engagement. In the first model we let the eight primary factors of self-efficacy predict work engagement, while the second model was designed to let a second-order self-efficacy factor predict work engagement.

The first-order model revealed that only two of the eight dimensions were significantly related to work engagement, namely instructional leadership and administrative management. Because such a result may be due to multicollinearity between the latent dimensions of self-efficacy, we also conducted separate SEM analyses of the relation between each of the eight dimensions of self-efficacy and work engagement. All regression weights significantly predicted work engagement. Nevertheless, the regression coefficients showed that the strongest predictor of engagement was 
instructional leadership, followed by administrative management and school environment. Although this finding should be confirmed in future research, we may speculate that these three areas of functioning are perceived to be the most important and that self-efficacy for these functions, particularly instructional leadership, are therefore most strongly related to engagement. However, recent research shows that Norwegian school principals experience heavy workloads and serious time pressure and that they find little time for instructional leadership (OECD 2009). We may speculate that this may lead to both a lack of instructional leadership in public schools and to a reduced engagement among school principals. For this reason, we propose that the role and responsibilities of school principals must be examined, with the purpose of reducing the range of responsibilities to allow room for the execution of instructional leadership and the development of adaptive learning environments in schools.

The result of the analysis of the second-order model confirmed a positive relation between self-efficacy and work engagement. In this model, self-efficacy predicted work engagement with a standardized estimate of .48. The analyses of both the firstand second-order models are in accordance with previous findings of a moderate to strong relation between self-efficacy and work engagement (e.g. Bakker et al. 2006; Breso et al. 2008; Halbesleben 2010; Prieto 2009; Sweetman and Luthans 2010), which demonstrates that this relation is also strong for school principals. Although this result supports the notion that self-efficacy is important for principals' engagement in their work, firm conclusions about the causal direction cannot be drawn from the model testing. Schaufeli and Bakker (2004) state that although self-efficacy and work engagement are positively related, it is not clear whether self-efficacy precedes or follows engagement. They suggest that an upward spiral may exist; self-efficacy breeds engagement, which in turn increases self-efficacy, and so on.

Previous research has documented that work engagement has implications for employees' performance and is related to positive attitudes towards work (e.g. job satisfaction and commitment). Engaged employees bring their full potential into their jobs and go beyond the formal structures of their position to take initiative (Demerouti et al. 2001a; Leiter and Bakker 2010; Schaufeli and Bakker 2004). Such characteristics may be especially useful in professions that deal with a variety of tasks and relationships. Principals have to relate to a number of areas of functioning and variety of people in their work environment such as teachers and students. We may speculate that creating and sustaining a work environment that promotes work engagement may have a positive impact for the exercising of not only the principal and teacher professions, but also for student outcomes. Such assumptions should be investigated in future research.

The present study has several limitations. First, the concepts used in this study do not operate in isolation from other psychological determinants that may affect principals' motivation and performance. Other constructs should be explored in relation to those included in this study. Second, future research should investigate the causal relations between self-efficacy and work engagement by means of longitudinal studies. Another limitation is the probability that the sample size influenced the results. Both the factor structure of the NPSES and the relation with work engagement need to be verified with larger samples. We should also note that the Norwegian Principal Self-Efficacy Scale has not yet been tested in other cultures outside of Norway. We consider that the 
eight dimensions constituting the NPSES could apply to all principals, although future research should verify the factor structure of the instrument in different contexts and cultures. Furthermore, even though the existence of the eight dimensions was empirically supported, other possible dimensions of principal self-efficacy should also be explored in future research.

Enhancing principals' self-efficacy and work engagement is an important objective for those responsible for improving the quality of leadership in schools. Norwegian principals' work is often described in terms of being demanding, hectic and unpredictable, in part because the curriculum and educational policy are often subject to change. Such changes require principals to be updated at any time in order to act efficaciously. Self-efficacy and engagement contribute positively to this functioning because they affect performance of the principals through mechanisms such as choice, effort, perseverance, initiative and extra-role behavior. In our view, providing both self-efficacy and work engagement is an important goal in the education of school principals. We also propose that the role and responsibilities of principals should be analyzed and designed to give realistic challenges and opportunities to conduct their responsibilities adequately. Additionally, future research should investigate the antecedents to a robust sense of principal self-efficacy and work engagement, and identify possible outcomes for schools, teachers and students.

\section{Appendix}

The 22 items of the Norwegian Principal Self-Efficacy Scale (NPSES)

How certain are you that you can:

Instructional leadership:

...develop this school's instructional platform.

...initiate, plan and carry out instructional development.

Economic management

...keep track of the school's finances.

...be sure that the finances of the school are under control.

Administrative management

...follow up and implement all decisions taken.

...have an ongoing evaluation of all activities at school and follow these up.

...always use your management prerogatives in relation to your employees in a constructive manner.

...facilitate work conditions for your staff in such a way that the work can be done constructively.

Teacher support

...support and assist teachers with challenges or problems.

...attend to and support teachers who are struggling with strain or exhaustion. 
Parental relations

...collaborate with the parents' representatives.

...develop a good cooperation between school and home.

School environment

...develop a school in which all teachers experience well-being.

...engage your employees in their professional development.

...develop a good psychosocial environment for the pupils.

...engage the pupils to take responsibility to make the school a better place to learn.

...develop a school that is open and welcoming to the pupils.

Relation to municipal authority

...promote the school's needs to the municipal authority.

...collaborate with the municipal authority about future directions for the school.

\section{Relation to local community}

...use resources in the community (people and areas).

...ensure that the school has contact with various groups and institutions in the community.

...maintain contact and cooperate with local businesses.

Open Access This article is distributed under the terms of the Creative Commons Attribution Noncommercial License which permits any noncommercial use, distribution, and reproduction in any medium, provided the original author(s) and source are credited.

\section{References}

Arbuckle, J. L. (2009). Amos 17.0 user's guide. United States of America: Amos Development Corporation.

Ashton, P. T., \& Webb, R. B. (1986). Making a difference: Teacher's sense of efficacy and student achievement. New York: Longman.

Bakker, A. B. (2009). Building engagement in the workplace. In R. J. Burke \& C. L. Cooper (Eds.), The peak performing organization. Oxon, UK: Routledge.

Bakker, A. B., Gierveld, J. H., \& Rijswijk, K. V. (2006). Succesfactoren bij vrouwelijke schoolleiders in het primair onderwijs: Een onderzoek naar burnout, bevlogenheid en prestaties [Success factors among female school principals in primary teaching: A study on burnout, work engagement, and performance]. Diemen, The Netherlands: Right Management Consultants.

Bakker, A. B., Schaufeli, W. B., Leiter, M. P., \& Taris, T. W. (2008). Work engagement: An emerging concept in occupational health psychology. Work \& Stress, 22(3), 187-200.

Bandura, A. (1977). Self-efficacy-toward a unifying theory of behavioral change. Psychological Review, 84(2), 191-215.

Bandura, A. (1982). Self-efficacy mechanism in human agency. American Psychologist, 37(2), 122-147.

Bandura, A. (1986). Social foundations of thought and action: a social cognitive theory. Englewood Cliffs, N.J.: Prentice-Hall.

Bandura, A. (1993). Perceived self-efficacy in cognitive development and functioning. Educational Psychologist, 28(2), 117-148.

Bandura, A. (1994). Self-Efficacy. In V. S. Ramachaudran (Ed.), Encyclopeida of human behavior, (Vol. 4, pp. 71-81). San Diego: Academic Press.

Bandura, A. (1997). Self-efficacy: The exercise of control. New York: Freeman.

Bandura, A. (2001). Social cognitive theory: An agentic perspective. Annual Review of Psychology, 52, 1-26. 
Bandura, A. (2005). Guide for constructing self-efficacy scales. In F. Pajares \& T. C. Urdan (Eds.), Self-efficacy beliefs of adolecents (pp. 307-337). Greenwich: Information Age Publishing.

Bandura, A. (2006a). Adolecent development from an agentic perspective. In F. Pajares \& T. Urdan (Eds.), Self efficacy beliefs of adolecents. Greenwich: Information Age.

Bandura, A. (2006b). Toward a psychology of human agency. Perspectives on Psychological Science, 1(2), 164-180.

Benestad, E. M., \& Pleym, T. (2006). Rektor, en moderne bedriftsleder, eller den forste blant likemenn? København: Handelshøgskolen i København.

Bong, M., \& Skaalvik, E. M. (2003). Academic self-concept and self-efficacy: How different are they really? Educational Psychology Review, 15(1), 1-40.

Brama, R. (2004). The professional self-Efficacy of school principals. Jerusalem: Hebrew University in Jerusalem.

Breso, E., Schaufeli, W. B., \& Salanova, M. (2008). Can a self-efficacy-based intervention decrease burnout, increase engagement and enhance performance? A quasi experimental study (manuscript submitted for puclication.)

Brown, S. D., \& Lent, R. W. (2005). Preparing adolescents to make career decisions: A social cognitive perspective. In F. Pajares \& T. C. Urdan (Eds.), Self-efficacy beliefs of adolescents.. Greenwich, CT: Information Age Publishing.

Byrne, B. M. (2010). Structural equation modeling with AMOS: Basic concepts, applications, and programming. New York: Routledge.

Chemers, M. M., Watson, C. B., \& May, S. T. (2000). Dispositional affect and leadership effectiveness: A comparison of self-esteem, optimism, and efficacy. Personality and Social Psychology Bulletin, 26(3), 267-277.

Demerouti, E., Bakker, A. B., de Jonge, J., Janssen, P. P. M., \& Schaufeli, W. B. (2001). Burnout and engagement at work as a function of demands and control. Scandinavian Journal of Work Environment \& Health, 27(4), 279-286.

Demerouti, E., Bakker, A. B., Nachreiner, F., \& Schaufeli, W. B. (2001). The job demands-resources model of burnout. Journal of Applied Psychology, 86(3), 499-512.

Dimmock, C., \& Hattie, J. (1996). School principals' self-efficacy and its measurement in a context of restructuring. School Effectiveness and School Improvement, 7(1), 62-75.

Forsyth, P. B., \& Hoy, W. K. (1978). Isolation and alienation in educational organizations. Educational Administration Quarterly, 14(1), 80-96.

Gist, M. E., \& Mitchell, T. R. (1992). Self-efficacy-a theoretical-analysis of its determinants and malleability. Academy of Management Review, 17(2), 183-211.

Goddard, R. D., Hoy, W. K., \& Hoy, A. W. (2000). Collective teacher efficacy: Its meaning, measure, and impact on student achievement. American Educational Research Journal, 37(2), 479-507.

Halbesleben, J. R. B. (2010). A meta-analysis of work engagement: Relationships with burnout, demands, resources and consequences. In A. Bakker \& M. P. Leiter (Eds.), Work engagement. A handbook of essential theory and research. Hove and New York: Psychology Press.

Hallberg, U. E., \& Schaufeli, W. B. (2006). "Same same" but different? Can work engagement be discriminated from job involvement and organizational commitment? European Psychologist, 11(2), 119-127.

Hannah, S. T., Avolio, B. J., Luthans, F., \& Harms, P. D. (2008). Leadership efficacy: Review and future directions. The Leadership Quarterly, 19(6), 669-692.

Hoy, A. W., \& Davis, H. A. (2005). Teacher self-efficacy and its influence on the achievement of adolescents. In F. Pajares \& T. C. Urdan (Eds.), Self-efficacy beliefs of adolescents. Greenwich: Information Age Publishing.

Hu, L.-t., \& Bentler, P. M. (1999). Cutoff criteria for fit indexes in covariance structure analysis: Conventional criteria versus new alternatives. Structural Equation Modeling, 6(1), 1-55.

Imants, J. G. M., \& De Brabander, C. J. (1996). Teachers' and principals' sense of efficacy in elementary schools. Teaching and Teacher Education, 12(2), 179-195.

Jackson, D. L., Gillaspy, J. A., Jr, \& Purc-Stephenson, R. (2009). Reporting practices in confirmatory factor analysis: An overview and some recommendations. Psychological Methods, 14(1), 6-23.

Kahn, W. A. (1990). Psychological conditions of personal engagement and disengagement at work. Academy of Management Journal, 33(4), 692-724. 
Leiter, M. P., \& Bakker, A. (2010). Work-engagement: Introduction. In A. Bakker \& M. P. Leiter (Eds.), Work engagement. A handbook of essential theory and research. Hove and New York: Psycholgy Press.

Licklider, B. L., \& Niska, J. M. (1993). Improving supervision of cooperative learning: A new approach to staff development for principals. Journal of Personnel Evaluation in Education, 6(4), 367-378.

MacCallum, R. C., \& Austin, J. T. (2000). Applications of structural equation modeling in psychological research. Annual Review of Psychology, 51(1), 201-226.

Maslach, C., Schaufeli, W. B., \& Leiter, M. P. (2001). Job burnout. Annual Review of Psychology, 52, 397-422.

Muijs, D., \& Reynolds, D. (2002). Teachers' beliefs and behaviors: What really matters? Journal of Classroom Interaction, 37(2), 3-15.

Møller, J. (2004). Lederidentiteter $i$ skolen. Oslo: Universitetsforlaget.

Møller, J., \& Fuglestad, O. L. (2006). Ledelse i anerkjente skoler. Oslo: Universitetsforl.

OECD. (2009). Creating effective teaching and learning environments: first results from TALIS. OECD.

Osterman, K., \& Sullivan, S. (1996). New principals in an urban bureaucracy: A sense of efficacy. Journal of School Leadership, 6(6), 661-690.

Pajares, F. (1997). Current directions in self-efficacy research. In M. L. Maehr \& P. R. Pintrich (Eds.), Advances in motivation and achievement (Vol. 10, pp. 1-49). Greenwich: JAI Press.

Pajares, F. (2002). Overview of social cognitive theory and self-efficacy. Retrieved from http://www. emory.edu/education/mfp/eff.html.

Prieto, L. L. (2009). Exploring the power of self-efficacy at work: Some empirical studies from the social cogntive perspective. Jaume: Universitat Jaume.

Rothbard, N. P. (2001). Enriching or depleting? The dynamics of engagement in work and family roles. Administrative Science Quarterly, 46(4), 655-684.

Salanova, M., Agut, S., \& Peiro, J. M. (2005). Linking organizational resources and work engagement to employee performance and customer loyalty: The mediation of service climate. Journal of Applied Psychology, 90(6), 1217-1227.

Salanova, M., Llorens, S., Cifre, E., Martinez, I. M., \& Schaufeli, W. B. (2003). Perceived collective efficacy, subjective well-being and task performance among electronic work groups-an experimental study. Small Group Research, 34(1), 43-73.

Schaufeli, W. B., \& Bakker, A. (2004). UWES Utrecht work engagement scale. Preliminary manual. New York: Wiley.

Schaufeli, W. B., \& Bakker, A. (2010). Defining and measuring work engagement: Brining clarity to the concept. In A. Bakker \& M. P. Leiter (Eds.), Work engagement. A handbook of essential theory and research. Hove, New York: Psycholgy Press.

Schaufeli, W. B., Bakker, A. B., \& Salanova, M. (2006). The measurement of work engagement with a short questionnaire: A cross-national study. Educational and Psychological Measurement, 66(4), 701-716.

Schaufeli, W. B., Salanova, M., González-romá, V., \& Bakker, A. B. (2002). The measurement of engagement and burnout: A two sample confirmatory factor analytic approach. Journal of Happiness Studies, 3(1), 71-92.

Schaufeli, W. B., Taris, T. W., \& Rhenen, W. v. (2008). Workaholism, burnout, and work engagement: Three of a kind or three different kinds of employee well-being? Applied Psychology, 57(2), 173-203.

Schunk, D. H., \& Meece, J. L. (2005). Self-efficacy development in adolescence. In F. Pajares \& T. C. Urdan (Eds.), Self-efficacy beliefs of adolescents. Greenwich: Information Age Publishing.

Schunk, D. H., Pintrich, P. R., \& Meece, J. L. (2008). Motivation in education: Theory, research, and applications. Upper Saddle River, NJ: Pearson/Merrill Prentice Hall.

Sierman Smith, L. R. (2008). Character education leadership: An investigation of principal efficacy beliefs. Dissertation abstracts international section a: Humanities and social sciences. 68(7-A), 2008, pp. 2755. ISSN 0419-4209 (Print). ProQuest Information \& Learning, US.

Skaalvik, E. M., \& Skaalvik, S. (2007). Dimensions of teacher self-efficacy and relations with strain factors, perceived collective teacher efficacy, and teacher burnout. Journal of Educational Psychology, 99(3), 611-625.

Skaalvik, E. M., \& Skaalvik, S. (2010). Teacher self-efficacy and teacher burnout: A study of relations. Teaching and Teacher Education, 26(4), 1059-1069.

Smith, W. (2003). Principal self-efficacy and effective teaching and learning environments. School Leadership \& Management, 23(4), 505-508. 
Smith, W., \& Guarino, A. J. (2006). Confirmatory factor analysis of the principal self-efficacy survey (PSES). Academy of Educational Leadership Journal, 10(3).

Smith, W., Guarino, A. J., Strom, P., \& Adams, O. (2006). Effective teaching and learning environments and principal self-efficacy. Journal of Research for Educational Leaders, 3(2), 4-23.

Sonnentag, S. (2003). Recovery, work engagement, and proactive behavior: A new look at the interface between nonwork and work. Journal of Applied Psychology, 88(3), 518-528.

Sweetman, D., \& Luthans, F. (2010). The power of positive psychology: Psychological capital and work engagement. In A. Bakker \& M. P. Leiter (Eds.), Work engagement: A handbook of essential theory and research. Hove, New York: Psychology Press.

Tabachnick, B. G., \& Fidell, L. S. (2007). Using multivariate statistics. Boston: Pearson/Allyn and Bacon.

Tschannen-Moran, M., \& Gareis, C. R. (2004). Principals sense of efficacy: Assessing a promising construct. Journal of Educational Administration, 42(5), 573-585.

Tschannen-Moran, M., \& Gareis, C. R. (2005). Cultivating principals' self-efficacy: Supports that matter. Journal of School Leadership, 17(1), 89-114.

Tschannen-Moran, M., \& Hoy, A. W. (2001). Teacher efficacy: Capturing an elusive construct. Teaching and Teacher Education, 17(7), 783-805.

Van Etten, S., Pressley, M., McInerney, D. M., \& Liem, A. D. (2008). College seniors' theory of their academic motivation. Journal of Educational Psychology, 100(4), 812-828.

Xanthopoulou, D., Bakker, A. B., Demerouti, E., \& Schaufeli, W. B. (2007). The role of personal resources in the job demands-resources model. International Journal of Stress Management, 14(2), 121-141.

Zimmerman, B. J. (1995). Self-efficacy and educational development. In A. Bandura (Ed.), Self-efficacy in changing societies. Cambridge: Campridge University Press.

\section{Author Biographies}

Roger A. Federici is a Ph.D. candidate in the Department of Education, Norwegian University of Science and Technology, Trondheim, Norway. His research interests are in the area of motivation, self-concept, self-efficacy, and educational leadership.

Einar M. Skaalvik is Professor in the Department of Education, Norwegian University of Science and Technology, Trondheim, Norway. His research interests are in the area of motivation, self-conceptions, satisfaction, and well-being among students and teachers. 